\title{
Immunoradiometric assay of insulin, intact proinsulin and 32-33 split proinsulin and radioimmunoassay of insulin in diet-treated Type 2 (non-insulin-dependent) diabetic subjects
}

\author{
P.M.Clark ${ }^{1}$, J.C.Levy ${ }^{2}$, L.Cox ${ }^{1}$, M. Burnett ${ }^{2}$, R.C. Turner ${ }^{2}$ and C.N.Hales ${ }^{1}$ \\ ${ }^{1}$ Department of Clinical Biochemistry, Addenbrooke's Hospital, Cambridge, and ${ }^{2}$ Diabetes Research Laboratories, Radcliffe Infirmary, \\ Oxford, UK
}

\begin{abstract}
Summary. Plasma insulin, intact proinsulin and 32-33 split proinsulin measured by specific immunoradiometric assays and insulin and C-peptide measured by radioimmunoassay were measured during a constant infusion of glucose test in ten diet-treated subjects with a history of Type 2 (non-insulin-dependent) diabetes (termed diabetic subjects), mean fasting plasma glucose $6.0 \pm 1.0 \mathrm{mmol} / 1$ (mean $\pm \mathrm{SD}$ ), and 12 non-diabetic control subjects. Immunoreactive insulin concentrations measured by radioimmunoassay were $33 \%$ higher than insulin and $16 \%$ higher than the sum of insulin and its precursors by immunoradiometric assay. The diabetic and non-diabetic subjects had similar fasting concentrations of insulin, intact proinsulin and 32-33 split proinsulin. The ratio of fasting intact proinsulin to total insulin was greater in the diabetic than the non-diabetic group $12.0 \%(6.8-21.0 \%$, 1 SD range) and $6.3 \%(4.0-9.8 \%)$, respectively, $p<0.01)$, though the groups overlapped substantially. After glucose infusion, diabetic and non-diabetic subjects had similar intact proinsulin concentrations (geometric mean 4.9 and
\end{abstract}

$5.2 \mathrm{pmol} / \mathrm{l}$, respectively), but the diabetic group had impaired insulin secretion by immunoradiometric assay (geometric means 55 and $101 \mathrm{pmol} / 1, p<0.05$ ) or by radioimmunoassay C-peptide (geometric means 935 and $1410 \mathrm{pmol} / 1, p<0.05$ ), though not by radioimmunoassay insulin ( 87 and $144 \mathrm{pmol} / \mathrm{l}$, $p=0.12$ ), respectively. Individual immunoradiometric assay insulin responses to glucose expressed in terms of obesity were subnormal in nine of ten diabetic subjects. Radioimmunoassay insulin and C-peptide gave less complete discrimination (subnormal responses in six of ten and eight of ten, respectively). Thus, raised proinsulin and proinsulin:total insulin ratio are not necessarily a feature of mild diet-treated Type 2 diabetic patients with subnormal insulin responses to glucose.

Key words: Proinsulin, split proinsulin, immunoradiometric assay, Type 2 (non-insulin-dependent) diabetes mellitus, impaired Beta-cell function.
Plasma concentrations of proinsulin have been shown to be raised in some subjects with insulinomas [1], Type 2 (non-insulin-dependent) diabetic subjects [2-4] and nondiabetic subjects under corticosteroid stress [5], and raised plasma concentrations of the partially processed product 32-33 split proinsulin have also been found in Type 2 diabetes [6]. Due to the non-specificity of some conventional insulin radioimmunoassays (RIA), cross-reaction with intact proinsulin and 32-33 split proinsulin may lead to overestimation of true insulin concentrations $[6,7]$. Highly specific and sensitive monoclonal antibody based two-site immunoradiometric assays (IRMA) have recently been described for plasma insulin, intact proinsulin, 3233 split proinsulin and 65-66 split proinsulin [8]. These assays may be of particular use in the determination of Beta-cell function in Type 2 diabetic subjects. Plasma immunoreactive insulin concentrations in obese Type 2 diabetic subjects have been reported to be higher than in non-diabetic subjects. Using these specific assays it is possible to determine whether in Type 2 diabetes there are specific abnormal proportions of insulin precursor peptides which might suggest differences in proinsulin to insulin conversion or which might be of diagnostic use.

The contribution of intact and split proinsulin concentrations to the immunoreactive insulin as measured by a conventional polyclonal RIA can cause significant overestimation of plasma insulin concentrations in newly-diagnosed Type 2 diabetic subjects [6], and in an unselected group of white Caucasian and Asian Type 2 diabetic subjects [7]. Reduction of plasma glucose concentrations by diet has been shown to reduce the ratio of fasting proinsulin:total insulin [4,9], but whether these abnormalities are also present in subjects with a history of Type 2 diabetes but with minimal hyperglycaemia on a weightmaintaining diet has not been determined. This group is of interest since it has been suggested that an abnormal in- 
Table 1. Subject characteristics

\begin{tabular}{lcc}
\hline & Type 2 diabetic & Non-diabetic \\
\hline$n$ & 10 & 12 \\
Sex (male:female) & $9: 1$ & $5: 7$ \\
Age (years) & $57 \pm 5$ & $56 \pm 5$ \\
BMI (kg $\cdot \mathrm{m}^{-2}$ ) & $26.2 \pm 2.8$ & $24.7 \pm 2.8$ \\
Fasting plasma glucose (mmol/l) & $6.0 \pm 1.0$ & $4.8 \pm 0.4$ \\
\hline
\end{tabular}

Data are presented as mean $\pm 1 \mathrm{SD}$

tact proinsulin:insulin (PI) ratio may be an early characteristic of Type 2 diabetes [10]. While fasting plasma glucose in such individuals may in fact be strictly nondiabetic, they represent a group in whom the primary propensity to develop diabetes is less likely to be obscured by secondary effects of hyperglycaemia. We have therefore studied the insulin and proinsulin responses to a constant low-dose glucose infusion in a group of subjects with a history of Type 2 diabetes and minimal hyperglycaemia on diet treatment alone (for simplicity referred to henceforth as Type 2 diabetic subjects) and in a matched group of non-diabetic subjects, using both specific IRMA methods [8] and a sensitive, but less specific RIA method [11].

\section{Subjects, materials and methods}

\section{Subjects}

Ten subjects with a history of Type 2 diabetes were studied. At diag nosis, all had been diabetic by World Health Organisation (WHO) criteria with fasting plasma glucose greater than $7.8 \mathrm{mmol} / \mathrm{l}$ (means \pm SD $12.5 \pm 3.5 \mathrm{mmol} / 1$, range $7.9-17.3 \mathrm{mmol} / \mathrm{l}$ ). Diabetes at diagnosis had not been associated with an acute infection, endocrinological condition or pregnancy. Body mass index (BMI) at diagnosis was $28.4 \pm 3.9 \mathrm{~kg} \cdot \mathrm{m}^{-2}$, range $23.4-36.9 \mathrm{~kg} \cdot \mathrm{m}^{-2}$. After a period of diet treatment ( $5.0 \pm 2.8$ years, range $0.4-10$ years) during which subjects lost median $6 \%$, (range +18 to $-2 \%$ ) of their body weight, all had a fasting plasma glucose concentration below $8 \mathrm{mmol} / 1$. They were compared with 12 age- and obesity-matched non-diabetic subjects (Table 1). In addition, eight first degree relatives of Type 2 diabetic patients were studied of which four were male and four female, median age 57 years (range $47-62$ years), BMI $23.9 \pm 3.2 \mathrm{~kg} \cdot \mathrm{m}^{2}$. To show the normal relationship between Beta-cell function and obesity over a wider range than in the matched non-diabetic sub. jects, a further 16 non-diabetic subjects, five male and cleven female, mean age $43 \pm 4$ years, BMI $23.0 \pm 2.3 \mathrm{~kg} \cdot \mathrm{m}^{2}$, were included in Figure 1 , and in the calculation of the regression between insulin - glucose response and obesity.

\section{Protocol}

Subjects were studied after an overnight fast. Cannulae were inserted into an ante-cubital vein for infusions and an ipsilateral wrist or hand vein for taking blood samples, which were arterialised by heating the arm. Each subject had a constant $5 \mathrm{mg} \cdot \mathrm{kg}$ ideal body weight $(\mathrm{IBW})^{-1} \cdot \mathrm{min}^{-1}$ glucose infusion for $60 \mathrm{~min}$. IBW was as sessed from median frame of the Metropolitan Life Tables 1959 [12].

\section{Biochemical methods}

Plasma glucose was measured with a centrifugal analyser using a hexokinase method (COBAS-BIO, Roche, Welwyn Garden City, UK). Plasma insulin, intact proinsulin and $32-33$ and $65-66$ split proinsulins were measured by IRMA [8]. The sum of IRMA in-
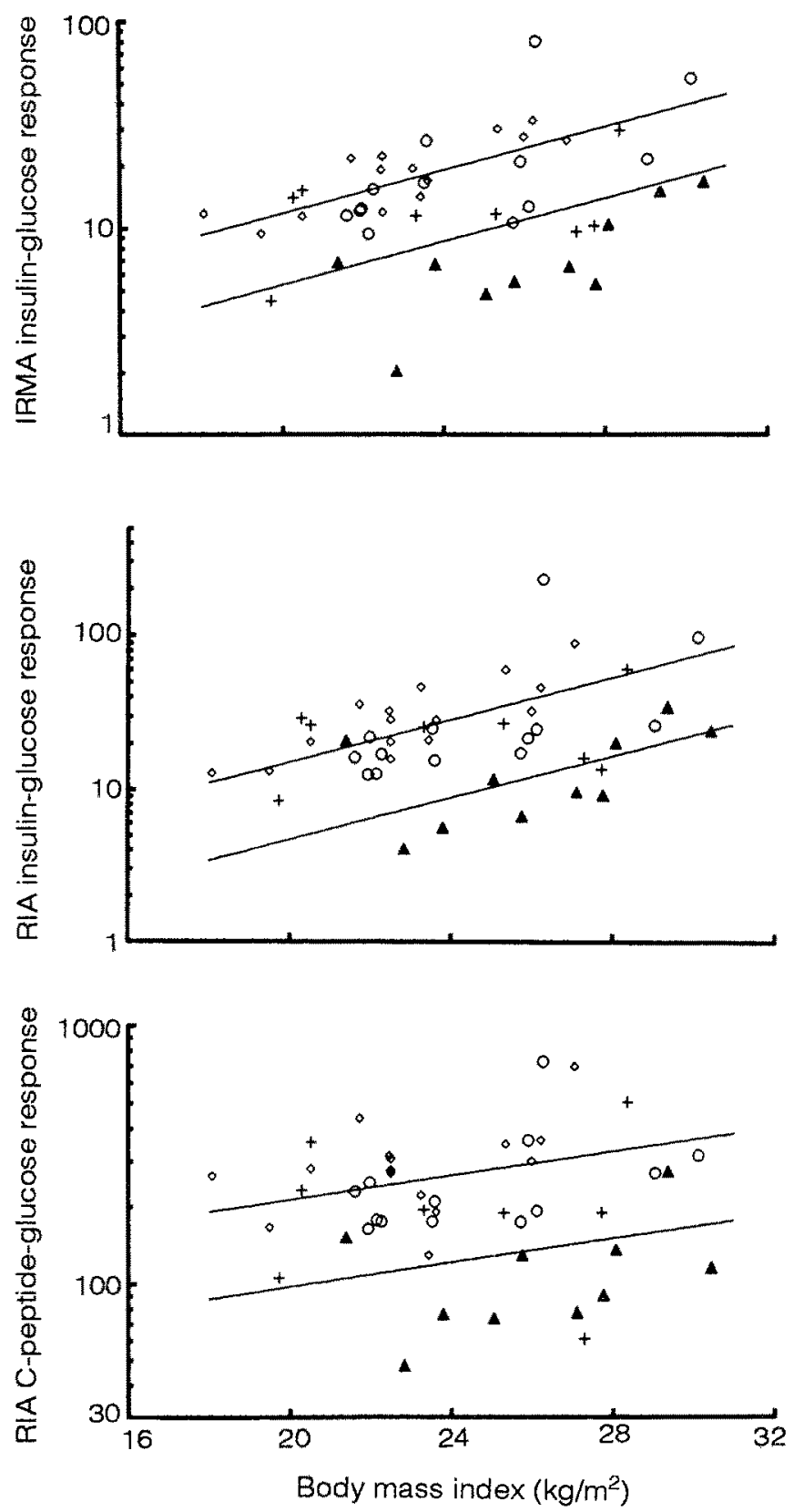

Fig. 1. Glucose-stimulated insulin responses during the glucose infusion as assessed by the insulin-glucose slope, using immunoradiometrically assayed insulin (IRMA) (top panel), radioimmunoassay (RIA) insulin (middle panel) and the C-peptide - glucose slope (bottom panel), plotted against body mass index (BMI) in 10 Type 2 (non-insulin-dependent) diabetic subjects (A) 12 age and obesity matched non-diabetic subjects $(O), 16$ other non-diabetic subjects $(\diamond)$ and eight first degree relatives of Type 2 diabetic subjects $(+)$. The upper lines in each panel represent the regression line through non-diabetic subjects with no family history of diabetes. The lower lines in each panel represent 2 SD below the regression line

sulin, 32-33 splilt proinsulin and intact proinsulin was termed total IRMA. Plasma insulin was also measured by a charcoal phase separation RIA using a laboratory guinea pig antiserum GPUR [11]. Plasma C-peptide was measured by a similar RIA using a Novo antiserum. Insulin standard was supplied by NIBSC, (Potters Bar, UK) and intact and split proinsulins by Eli Lilly and Co., (Indianapolis, Ind, USA). 


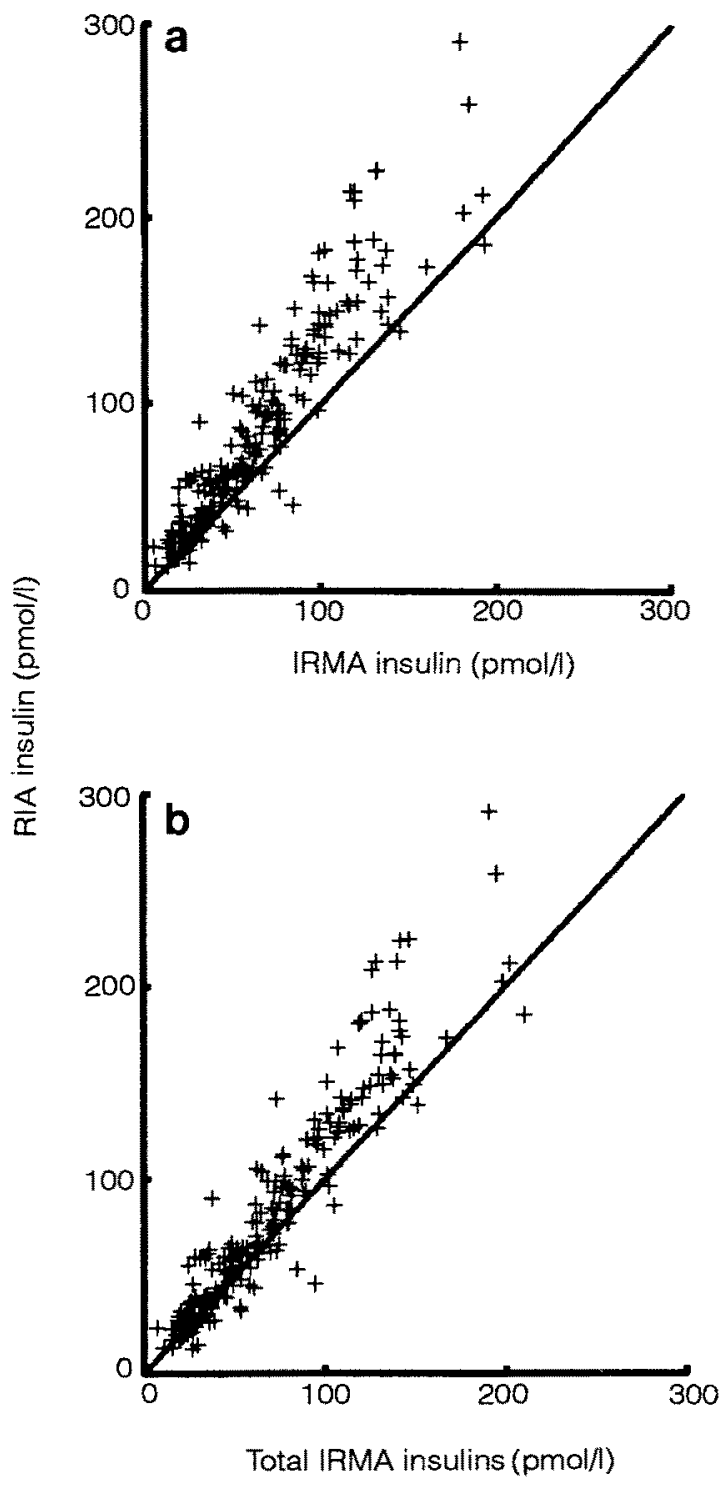

Fig. 2a,b. Immunoradiometrically (IRMA) assayed insulin vs radioimmunoassay (RIA) insulin (a) and total IRMA insulin and proinsulin species vs RIA insulin (b) measured on 220 different plas. ma samples. Dashed lines represent line of equivalence

\section{Calculations}

Fasting concentrations were taken from the mean of -5 and 0 min samples, and glucose-stimulated concentrations from the mean of 55 and 60 min samples of the glucose infusion. The PI ratio was calculated as the ratio of intact proinsulin to the sum of insulin, intact proinsulin and 32-33 split insulin as measured by IRMA. To assess the Beta-cell response, the vector slope of the insulin: glucose concentrations was calculated for both IRMA and RIA by linear regression through the insulin-glucose pairs at $-5,0,6,10,20,55$, and 60 min samples [13]. C-peptide vector slopes were calculated similarly. Values are presented as mean $\pm \mathrm{SD}$, or as geometric means (1 SD range) for insulin, proinsulin species, C-peptide and insulin: glucose rector slopes.

\section{Statistical analysis}

Statistical significance was assessed by group $t$-tests, using logarithmic transformation for insulin species and C-peptide. RIA and IRMA estimations of insulin were compared using difference anal- ysis [15]. Since the absolute difference between the assays increased with insulin concentration, values were transformed logarithmically, yielding a proportional bias quoted as geometric mean and $1 \mathrm{SD}$ range. The coefficient of variation (CV) of assay results from consecutive samples was assessed from the formula $\sqrt{ }\left(\sum\left(s_{1}-s_{2}\right)^{2} / 2 n\right)$ (square root of the mean estimated variance from duplicates).

\section{Results \\ Plasmaglucose}

Fasting plasma glucose levels in the Type 2 diabetic subjects controlled on diet alone were significantly raised compared with the non-diabetic subjects (mean $\pm 1 \mathrm{SD}$ $6.0 \pm 1.0$ and $4.8 \pm 0.4 \mathrm{mmol} / 1$, respectively, $p<0.01$, Table 1), as was plasma glucose after the 60 -min glucose infusion $(10.6 \pm 1.5$ and $8.8 \pm 0.9 \mathrm{mmol} / \mathrm{l}$, respectively $p<0.05$ ). In the first degree relatives, fasting plasma glucose was $5.0 \pm 0.4 \mathrm{mmol} / \mathrm{l}$ and after the $60-\mathrm{min}$ glucose infusion test was $9.9 \pm 0.9 \mathrm{mmol} / \mathrm{l}$.

\section{Plasma insulin}

Comparison of IRMA and RIA. Plasma insulin was measured by both IRMA and RIA on 220 separate plasma samples, taken fasting and during the course of the glucose infusion. RIA insulin correlated with IRMA insulin $(r=0.96)$, and gave higher results $(133 \%(101-175), 1 \mathrm{SD}$ range) compared with IRMA insulin (Fig.2). RIA insulin correlated with IRMA total insulin $(r=0.97)$ and gave slightly higher results $116 \%$ (90-149) (Fig. 2). This may be due to incomplete recovery in the IRMA assay [8]. Cross reactivity in the RIA insulin assay with both intact proinsulin and 32-33 split proinsulin standards was $100 \%$, and of $65-66$ split proinsulin $50 \%$.

Limitation of single plasma sample precision by biological variability. The intra-assay precision of IRMA and RIA assessed by coeficient of variation (C.V.) of duplicate measurements were each lower than $10 \%$. The precision of a single determination of insulin from a plasma sample is, however, also subject to biological and sampling variability. The C.V. of plasma insulin determinations by IRMA and RIA in repeated plasma samples at $5 \mathrm{~min}$ intervals was assessed in 23 subjects from the -5 and 10 min fasting samples, $(15.8 \%$ and by IRMA and $16.6 \%$ RIA), and for the 55 and 60 min samples of the glucose infusion, (10.8 and $9.3 \%$ respectively).

Comparison of diabetic and non-diabetic plasma insulin by IRMA and RIA (Fig.3). Fasting plasma insulin concentrations (geometric mean and $1 \mathrm{SD}$ range) were similar in the diabetic and non-diabetic subjects measured by IRMA (22 (11-45) and 27 (14-52) pmol/1 respectively) and by RIA (33 (15-71) and 31 (14-69) pmol/l, respectively). Plasma insulin after the 60-min glucose infusion was significantly lower in the diabetic than the non-diabetic subjects by IRMA (55 (34-90) and 101 (55-185) pmol/1 respectively, $p<0.05)$, but not significantly different by RIA (87 (47-159) and $144(64-324) \mathrm{pmol} / \mathrm{l}, p=0.12)$. 

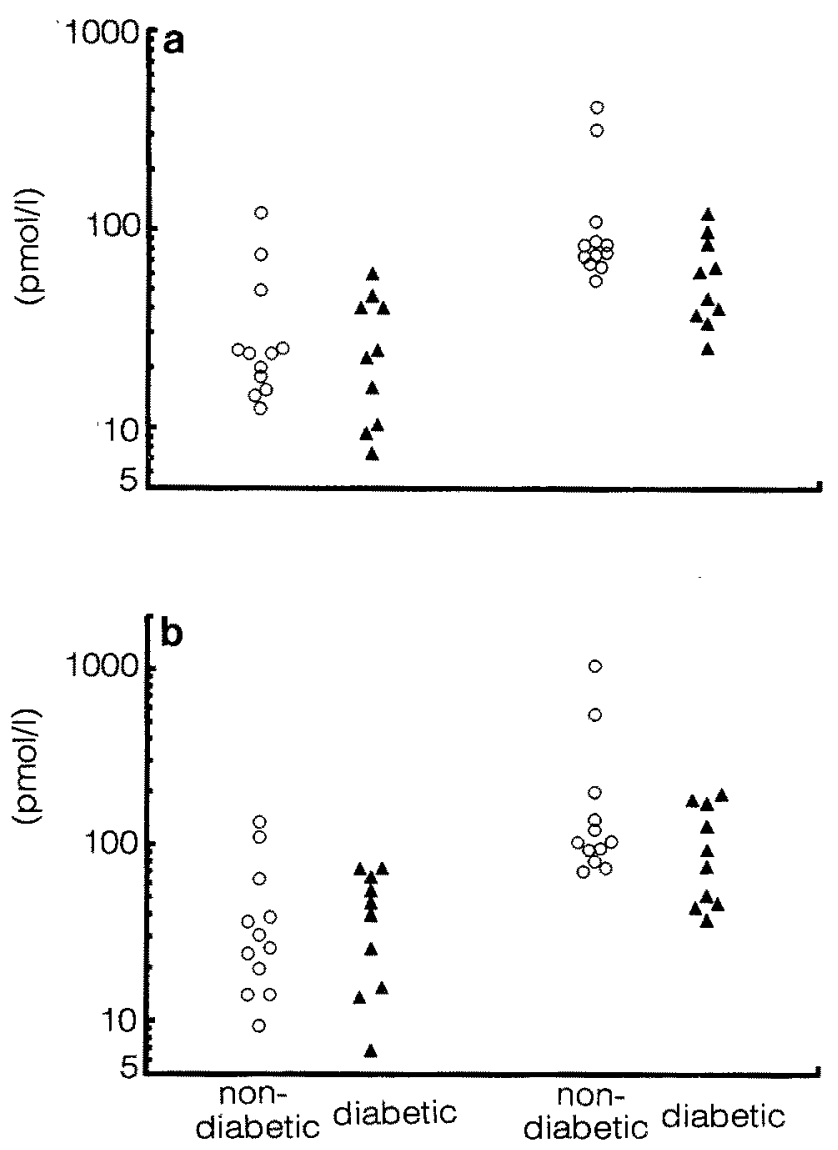

Fig.3a,b. Immunoradiometrically assayed insulin (a) and RIA insulin (b) in 12 non-diabetic (O) and 10 diet-treated diabetic subjects (A), fasting (left hand columns) and at the end of the 60-min continuous glucose infusion (right hand columns)

\section{Plasma intact proinsulin and 32-33 split proinsulin}

Plasma intact proinsulin (Fig. 4) and 32-33 split proinsulin concentrations were similar in the diabetic and nondiabetic groups, both fasting (intact proinsulin: 3.3 (1.76.4 ) and 2.1 (1.1-3.8) pmol/1, respectively; 32-33 split proinsulin: $2.0(0.9-4.7)$ and $3.0(1.5-6.0) \mathrm{pmol} / 1$, respectively), and at the end of the glucose infusion, (intact proinsulin: $5.0(2.0-11.8)$ and $4.7(2.6-8.5) \mathrm{pmol} / \mathrm{l}$, respectively; 32-33 split proinsulin: $4.1(1.5-11.4)$ and 6.4 (3.113.6) $\mathrm{pmol} / \mathrm{l}$, respectively). The concentration of fasting 65-66 split proinsulin was below the assay detection limit $(5 \mathrm{pmol} / \mathrm{l})$ and was therefore not included in the total insulin-like species.

\section{Proinsulins as a proportion of total insulin related peptides}

The PI ratio in the diabetic subjects was significantly greater than in the non-diabetic subjects both fasting $(12.0 \%(6.8-21.0)$ and $6.3 \%(4.0-9.8)$, respectively, $p<0.01$ ), and at the end of the glucose infusion $(7.8 \%$ (4.5-13.3) and $4.2 \%(3.2-5.4)$, respectively, $p<0.01$, though five of the ten diabetic subjects fell within the normal range. The PI ratio fell in both groups during the glucose infusion, but this was significant only in the non- diabetic group $(p<0.01)$. There was no difference between the diet-treated diabetic or the non-diabetic subjects in 32-33 split proinsulin when expressed as a percentage of the sum of insulin, intact proinsulin and 32-33 split insulin either fasting or after the glucose infusion.

\section{Plasma C-peptide}

Fasting plasma $\mathrm{C}$-peptide was similar in the diabetic and non-diabetic groups (507 (299-860) and 499 (307811) pmol/l, respectively), but at the end of the glucose infusion, plasma C-peptide was lower in the diabetic group (935 (632-1385) and 1410 (928-2142) pmol/l, respectively, $p<0.05)$.

\section{Beta-cell response assessed as insulin and C-peptide- glucose vector slopes}

The slope of the insulin:glucose response during the glucose infusion (vector slope) was significantly reduced in the Type 2 diabetic subjects compared with the nondiabetic subjects, both by IRMA (6.9 (3.9-12.2) and 17.9 (9.6-33.6) $\mathrm{pmol} / \mathrm{mmol} p<0.01$ ), and by RIA (12.1 (6.223.6) and $27.1(11.8-62.2) \mathrm{pmol} / \mathrm{mmol}$, respectively,
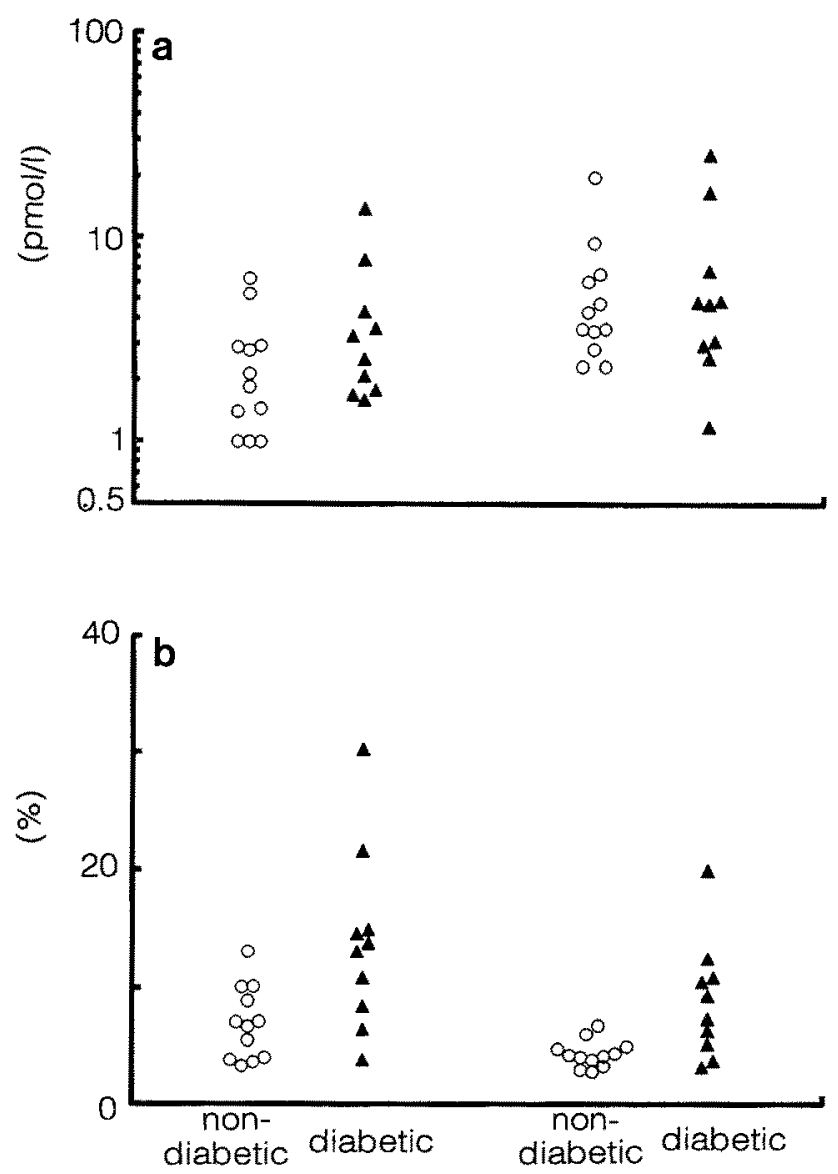

Fig. 4a,b. Intact proinsulin concentrations (a) and intact proinsulin expressed as a proportion of total insulin-like species (b) in 12 nondiabetic (O) and 10 diet-treated diabetic subjects ( $\mathbf{A}$ ), fasting (left hand columns) and at the end of the 60-min continuous glucose infusion (right hand columns) 
$p<0.05$ ). The vector slope is significantly correlated with obesity [12] and this relation is shown in Figure 1. If a subnormal insulin response in a subject is defined as an insulin-glucose slope less than 2 SD units below the normal mean value for the obesity (BMI) of that subject, when assessed by the IRMA insulin - glucose slope, nine of the ten diabetic subjects had a subnormal response. Assessed by RIA insulin-glucose slope, six of the ten diabetic subjects had a subnormal response (though if a single outlying normal subject with RIA vector slope $>3$ SD above the predicted value is excluded, eight of the ten diabetic subjects had a subnormal response).

The slope of the C-peptide - glucose response was significantly reduced in the diabetic, compared with the non-diabetic subjects: $104(66-166)$ and 240 (158$363) \mathrm{pmol} / \mathrm{mmol}$, respectively, $p<0.001$. Assessed with respect to obesity (BMI), eight of the ten diabetic subjects had a subnormal C-peptide-glucose response.

\section{First degree relatives}

The eight first degree relatives of Type 2 diabetic subjects had intact proinsulin, 32-33 split proinsulin and insulin concentrations which were not significantly different from those of the normal subjects. However, the Beta-cell response was subnormal in three of the first degree relatives assessed by IRMA insulin - glucose response, one by RIA and one by C-peptide (Fig. 1).

\section{Discussion}

Some polyclonal RIA methods for plasma insulin have high cross-reactivity for intact proinsulin and its partially processed products, which have significantly lower biological activities [16]. The development of a highly specific and sensitive two-site monoclonal immunoradiometric assay [8] means that insulin immunoreactivity by this method can more accurately represent "true" insulin concentration, particularly in situations when circulating concentrations of proinsulins are raised, such as insulinomas [1] or poorly-controlled diabetes $[2,14]$.

In the present study immunoreactive insulin concentrations as measured by RIA were significantly higher than insulin concentrations measured by IRMA, but were not significantly different from the sum of IRMA insulin, intact proinsulin and 32-33 split proinsulin concentrations, due to the cross-reactivity of proinsulins in the RIA. When intact and 32-33 split proinsulins make up only a small proportion of the total immunoreactive insulin, the RIA can be expected to provide similar information to the more specific IRMA.

IRMA techniques can be a more precise as well as a more accurate measure of insulin concentrations. In a clinical setting, however, the variability of plasma insulin estimates are influenced not only by the precision of the assay, but also by variability due to sample handling and storage and by the biological pulsatility of plasma insulin, both in non-diabetic [17] and diabetic subjects [18]. The between-sample variation in samples taken 5-min apart was estimated by the two assay techniques, and found to be similar both fasting and at the end of the glucose infusion.

Significant overestimation of pancreatic function due to the cross-reactivity of a conventional RIA method to raised proinsulin concentrations has been shown in newlydiagnosed Type 2 diabetic subjects studied by Temple et al. [6], particularly in the more obese group. However, the fact that these subjects were untreated, and were likely to be under a significant degree of hyperglycaemia-induced pancreatic stress, may have raised the proinsulin: total immunoreactive insulin, which has been shown to decrease during treatment $[4,9]$. In the present study, subjects were selected to represent the less severe end of the spectrum of Type 2 diabetes, having a relatively short duration of disease, and being controlled on a weight-maintaining diet. From the time of diagnosis the diabetic subjects had lost a median of $6 \%$ body weight with a reduction of fasting plasma glucose to near normal concentrations. Though the effect of such a weight loss per se on the proportion of proinsulin to insulin in plasma is not known, the fall in plasma glucose would be expected to reduce the possibility of deleterious effects of hyperglycaemia on Betacell function $[19,20]$. Indeed, some of the subjects with a previous diagnosis of diabetes had fasting glycaemia below the WHO limit of $7.8 \mathrm{mmol} / \mathrm{l}$ for diabetes at the time of testing. Any abnormalities in this group with a proven propensity to Type 2 diabetes would be expected to be especially relevant to aetiology.

Fasting plasma insulin concentrations were similar in the diabetic and the non-diabetic subjects, whether measured by IRMA or RIA. After $60 \mathrm{~min}$ of the glucose infusion, the mildly diabetic group had a lower mean plasma insulin than the non-diabetic group when assessed by IRMA and a lower C-peptide, though there was considerable overlap between individual values in the two groups. Mean RIA insulin concentrations, on the other hand, were less different between the two groups. Intact proinsulin and 32-33 split proinsulin concentrations were similar both fasting and at the end of the glucose infusion.

It has been suggested that the ratio of proinsulin to total insulin immunoreactivity might be a sensitive method of diagnosing the earliest stages of Beta-cell dysfunction [5]. This ratio is raised in newly-diagnosed Type 2 diabetic subjects [6], and falls with treatment of hyperglycaemia $[4,9]$. In the present data, the basal group mean PI ratio was higher in the mildly hyperglycaemic subjects with a history of diabetes than the non-diabetic subjects. However, there was a considerable overlap in the individual values in the two groups. After the glucose infusion, there was again a large scatter and overlap between the groups.

The lack of a clear separation of the two groups by the stimulated insulin, proinsulin or C-peptide concentrations does not mean that some mildly diabetic subjects had normal insulin secretory responses. The insulin response to glucose must be assessed in the light of both the degree of glycaemia provoking the response, and the prevailing degree of insulin sensitivity, whether measured by fasting insulin concentrations [21], obesity [13, 22] or other measures [23]. When the slope of the insulin-glucose response was expressed in relation to obesity [13] using 
IRMA insulin, nine of the ten diabetic subjects had a subnormal pancreatic response. Use of RIA insulin - glucose response slopes was less discriminatory, though six of the ten subjects had a subnormal response. With the C-peptide-glucose response slopes, eight of the ten subjects had a subnormal response, and the general pattern of responses was similar with all the assays.

The separation in insulin responsiveness between the two groups contrasts with the relatively greater degree of overlap between the proinsulin: total immunoreactive insulin ratio measured fasting or after the glucose infusion. Though the mean PI ratio in this group with a history of Type 2 diabetes was raised, this was not as sensitive a marker of Beta-cell dysfunction as their impaired obesity-corrected insulin-glucose response. Due to the mild hyperglycaemia of the diabetic group as a whole, it is not possible from these data to determine whether the tendency of some diabetic subjects to secrete relatively more proinsulin than insulin is a primary feature of Beta-cell dysfunction, or is secondary, possibly to hyperglycaemia.

The examination of the IRMA insulin - glucose responses of eight first degree relatives in relation to their degree of obesity identifies three as having subnormal responses. It is possible that these individuals, though normoglycaemic and without a history of hyperglycaemia, might have inherited a component of the diabetic genotype and be at a higher risk of developing diabetes. Only long-term follow-up of subjects identified in this way will be able to validate this hypothesis.

Acknowledgements. The authors would like to acknowledge the expert technical assistance of Mr. M.Brown, Ms. D.Wong, Ms. A. Schneider, and are grateful to the Medical Research Council, British Diabetic Association, Lilly and SmithKline-Beecham Ltd. for financial support.

\section{References}

1. Gutman RA, Lazanus NR, Penhos JC, Fajans SS, Recant L (1971) Circulating proinsulin-like material in patients with functioning insulinomas. N Engl J Med 284: 1003-1008

2. Duckworth WC, Solomon SS, Kitabchi AE (1972) Effect of chronic sulphonylurea therapy on plasma insulin and proinsulin levels. J Clin Endocrinol Metab 35: 585-591

3. Gorden P, Hendricks CM, Roth J (1974) Circulating proinsulinlike component in man: increased proportion in hyperinsulinaemic states. Diabetologia 10: 469-474

4. Mako ME, Starr JI, Rubenstein AH (1977) Circulating proinsulin in patients with maturity-onset diabetes. Am J Med 63:865869

5. Ward WK, LaCava EC, Paquette TL, Beard JC, Wallum BJ, Porte D Jr (1987) Disproportionate elevation of immunoreactive proinsulin in Type 2 (non-insulin-dependent) diabetes mellitus and in experimental insulin resistance. Diabetologia 30: 698-702

6. Temple RC, Carrington CA, Luzio SD, et al. (1989) Insulin deficiency in non-insulin-dependent diabetes. Lancet I: 293-295

7. Temple RC, Clark PMS, Nagi DK, Schneider AE, Yudkin JS, Hales CN (1990) Radioimmunoassay may overestimate insulin in non-insulin-dependent diabetics. Clin Endocrinol 32: 689-693
8. Sobey WJ, Beer SF, Carrington CA, et al. (1989) Sensitive and specific two-site immunoradiometric assays for human insulin, proinsulin, 56-66 split and 32-33 split proinsulins. Biochem $J$ 260:535-541

9. Yoshioka N, Kuzuya T, Matgsuda A, Taniguchi M, Iwamoto $Y$ (1989) Effects of dietary treatment on serum insulin and proinsulin response in newly diagnosed NIDDM. Diabetes 38: 262266

10. Porte D Jr, Kahn SE (1989) Hyperproinsulinemia and amyloid in NIDDM. Clues to etiology of islet Betarcell dysfunction? Diabetes 38: 333-336

11. Albano JDM, Ekins RP, Maritz G, Turner RC (1972) A sensitive, precise radioimmunoassay of serum insulin relying on charcoal separation of bound and free hormone moieties. Acta Endocrinol 70: 487-509

12. Metropolitan Life Insurance Company (1959) New weight standards for men and women. Statis Bull 40: $1-6$

13. Levy JC, Rudenski A, Burnett M, Knight R, Matthews DR, Turner RC (1991) Simple empirical assessment of Beta-cell function by a constant infusion of glucose test in normal and Type 2 (noninsulin-dependent) diabetic subjects. Diabetologia 34: 488-499

14. Yoshioka N, Kuzuya T, Matsuda A, Taniguchi M, Iwamoto $Y$ (1988) Serum proinsulin levels at fasting and after oral glucose load in patients with Type 2 (non-insulin-dependent) diabetes mellitus. Diabetologia 31: 355-360

15. Bland JM, Altman DG (1986) Statistical methods for assessing agreement between two methods of clinical measurement. Lancet I: $307-310$

16. Revers RR, Henry R, Schmeiser L et al. (1984) The effects of biosynthetic human proinsulin on carbohydrate metabolism. Diabetes 33: 762-770

17. Lang DA, Matthews DR, Peto J, Turner RC (1979) Cyclic oscillations of basal plasma glucose and insulin concentrations in human beings. N Engl J Med 301: 1023-1027

18. Lang DA, Matthews DR, Turner RC (1981) Brief, irregular oscillations of basal plasma insulin and glucose concentrations in diabetic man. Diabetes 30: 435-439

19. Bonner-Weir S, Trent DF, Weir GC (1983) Partial pancreatectomy in the rat and subsequent defect in glucose-induced insulin release. J Clin Invest 71: 1544-1553

20. Rosetti L, Shulman GI, Zawalich W, DeFronzo RA (1987) Effect of chronic hyperglycemia on in vivo insulin secretion in partially pancreatectomized rats. J Clin Invest 80: 1037-1044

21. Bagdade JD, Bierman EL, Porte D Jr (1967) The significance of basal insulin levels in the evaluation of the insulin response to glucose in diabetic and nondiabetic subjects. J Clin Invest 46 : $1549-1557$

22. Karam JH, Grodsky GM, Pavlatos FC, Forsham PH (1965) Critical factors in excessive serum-insulin response to glucose. Obesity in maturity-onset diabetes and growth hormone in acromegaly. Lancet I: 286-289

23. Bergman RN, Phillips LS, Cobelli C (1981) Physiologic evaluation of factors controlling glucose tolerance in man: measurement of insulin sensitivity and Beta-cell glucose sensitivity from the response to intravenous glucose. J Clin Invest 68: 1456-1467

Received: 29 October 1991

and in revised form: 30 December 1991

Dr.J.C.Levy

Diabetes Research Laboratories

Radcliffe Infirmary

Woodstock Road

Oxford OX2 6HE

UK 